\title{
Evaluation of "Life with Diabetes" Patient Education Booklets
}

FREDRIC M. WOLF, PhD

Assistant Professor of Postgraduate Medicine and Health Professions Education

Associate Director of Educational Development and Evaluation

University of Michigan Medical School

Ann Arbor
LISA SYLVEST SHERWOOD, BSN

Assistant Head Nurse, Diabetes Center Unit;

PATRICIA A. BARR, BS

Assistant Manager of Media,

Educational Development and Evaluation Core; MARTHA M. FUNNELL, RN, MS

Clinical Nurse Specialist, Diabetes Center Unit

all of the Diabetes Research and Training Center

Ann Arbor, Michigan
Evaluation of written patient education materials is a necessary part of providing education to patients with diabetes. Evaluation, however, is useful only if the needs of both those who use the materials (patients) and those who recommend and distribute the materials (health care professionals) are considered. Eight booklets in the "Life with Diabetes" patient education series (developed by the Michigan Diabetes Research and Training Center) were evaluated by both health professionals and patients. Twenty-eight to 37 health professionals including nurses, dietitians, and physicians evaluated each booklet. Their comments were used to revise and improve the booklets before publication (formative or process evaluation).
The increasing importance of evaluation in monitoring the efficacy of diabetes patient education programs is evidenced by the inclusion of evaluation in recent guidelines published by the American Association of Diabetes Educators, American Diabetes Association, and Centers for Disease Control. ${ }^{1-3}$ These guidelines focus on the educational components needed to provide quality care and emphasize the content in which patients need to become competent. Methods for assessing this competence in terms of patients' knowledge, self-care skills and behavior, and attitudes are stressed. The assessment of impact of patient education is often termed summative evaluation..$^{4-5}$ The purpose is to assess whether patient education makes a difference and, if so, how much of a difference and in which precise ways. This often is referred to as evaluation of the outcomes of ongoing programs and has as its central purpose the judgment of a program's overall merit. Assessment of instruction and testing instruments also is considered a component of this evaluation process.

Perhaps surprisingly, no mention is made of the evaluation of educational materials used for patient education in the guidelines published by these organizations. ${ }^{1-3}$ Evaluation of instructional materials or methods often is performed on a continuing basis and is called process or formative evaluation..$^{4-6}$ Its aim is to bolster the quality of an educational program by revising materials and methods based on evidence obtained during the construction and pilot testing of the program or materials. A comprehensive evaluation would strive to include both summative and formative components.

Supported in part by NIH Grant No. 5 P60 AM 20572, National Institute of Arthritis, Diabetes, and Digestive and Kidney Diseases.

Reprint requests to Dr. Fredric M. Wolf, Michigan Diabetes Research and Training Center, University of Michigan Medical School, G1208 Towsley Center (Box 57), Ann Arbor, MI 48109.

\section{Acknowledgments}

We thank the anonymous reviewers and James W. Pichert and Leora L. Wolf for their helpful comments and suggestions: Scarlett Bennett for assistance with data entry; and Deborah Patt for technical assistance in the preparation of this manuscript. 
Table 1. Current Titles in "Life with Diabetes" BookJets

\author{
* Diabetes Defined \\ * Insulin \\ * Oral Antidiabetes Medications \\ * Urine Testing \\ * Diabetes and Pregnancy \\ * Long-Term Complications \\ * Resources for You \\ * Leaming to Live with Diabetes \\ Personal Health Habits for People with Diabetes \\ Diabetes: A Book for Children \\ Diabetes: A Book for Parents \\ Diabetic Retinopathy and Its Treatment by Laser \\ Sexual Health and Diabetes \\ Monitoring Your Diabetes \\ Insulin Pump Therapy-Is It for You? \\ Exercising for Relaxation and Fitness: The Easy \\ Does It Program with Special Tips for People \\ with Diabetes and Heart Disease
}

*Booklets included in present evaluation

The present study evaluates eight of 16 titles in the "Life with Diabetes" patient education booklet series produced by the University of Michigan Diabetes Research and Training Center (MDRTC). ${ }^{7}$ (The newest booklets in the series were developed after this evaluation was completed.)

\section{Description of Booklets}

The series of booklets was developed to coincide with a series of patient education classes for people with diabetes. Each booklet provides specific information about a single concept related to diabetes self-care and supplements the information presented in the classes, also providing a resource for patients after their retum home. The booklets were written by one or more health professionals who were actively involved with the classes and/or interacting clinically with the patients, and each author is considered highly knowledgeable in the specific area of diabetes about which he or she has written. A complete listing of titles is provided in Table 1 .

Table 2. Job Responsibility and Practice Location of Health Professional Evaluators

Evaluator Evaluators

Characteristic

(\%)

Job responsibility

Nurse

61

Dietitian

26

Physician

Other

Practice location

Hospital-based

Public health department

Office

82

\section{Evaluation Design}

Following internal review by MDRTC health professionals and members of the patient education committee, 28 to 37 health professionals evaluated each of the booklets before publication as part of a formative evaluation. From 17 to 24 nurses, eight to 10 dietitians, and either one or two physicians critically reviewed each booklet. The number of evaluators exceeded the minimum number of 20 recommended by the US Department of Health and Human Services. ${ }^{8}$ The job responsibilities and practice locations of these evaluators are given in Table 2 . Most $(61 \%)$ were nurses, followed by dietitians (26\%), and physicians (5\%). Most were hospital-based health professionals $(82 \%)$, some working in a department of public health (15\%). A few were based in private offices (3\%). The instrument used by each evaluator included 5-point Likerttype scales ranging from "completely agree" to "strong reservations." Each booklet was rated on nine distinct categories, with space provided for specific comments.

Summative evaluation comprises two components corresponding to patients' knowledge and attitudes. Attitudes were assessed through 149 evaluation questionnaires completed by patients consecutively admitted to the Diabetes Center Unit (DCU). This questionnaire was designed to measure attitudes toward the utility of these booklets. The instrument included 5-point Likert-type scales ranging from " not at all" to "extremely" to rate six aspects of each booklet. The highest level of formal education for these patients was elementary school (7\%), high school $(73 \%)$, or college $(20 \%)$. Patients completed these evaluation questionnaires anonymously to enhance the likelihood of their giving more openly frank critiques of the booklets. Because patients were recruited into the study consecutively, it is likely that they reflected the broader untested population of patients seen in the DCU.

These patients typically are referred to our tertiary care medical center because of uncontrolled diabetes (ie, very high blood sugar). The DCU database indicated that of the entire DCU population, about $58 \%$ are female and $42 \%$ male; about $40 \%$ have type I and $60 \%$, type II diabetes; and about $88 \%$ are treated with insulin, $7 \%$ with oral medication, and $5 \%$ with diet only. Average age was about 48 years, and the average length of stay on the DCU was 10 days.

\section{Results}

Over $90 \%$ of the health professional evaluators agreed either mostly or completely that the information in the booklets was current, accurate, appropriate to the target audience, well organized, paced appropriately, and presented in an interesting manner, with clear titles, words, and illustrations. The only category in which over $10 \%$ of the evaluators did not mostly or completely agree was in recommending use of the material for patients in their own practice; as some booklets are specificfor certain types of patients (eg, pediatrics), they would clearly be inappropriate for use in the practice of health professionals in other fields (Table 3).

A minimum of $89 \%$ of patient responses rated the booklets as moderately to extremely easy to read and understand, meeting their need for information on the topic, useful in taking care of their diabetes, and containing drawings and information helpful for improving the way they care for their diabetes (Table 4). Additional comments regarding individual booklets included specific suggestions for change and generally 
Table 3. Average Percentage of Responses in Health Professionals' Evaluation of Education Booklets

\section{Evaluation Category}

1. Information current

2. Information accurate

3. Level appropriate to target audience

4. Material well organized

5. Pace appropriate

6. Length appropriate

7. Material presented in an interesting manner

8. Titles, words, and illustrations clear

9. I would recommend use of this material by patients in my practice

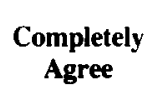

74

71

76

87

81

74

70

82

73
Mostly Agree

21

23

20

12

18

21

22

17

17
Acceptable

2

3

3

1

1

4

7

1

4

\section{Some}

Reservations

2

4

1

0

.

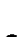

2

1

0

0

0

Note: Between 28 and 37 health professionals evaluated each booklet.

\section{Table 4. Average Percentage of Responses in Patients' Evaluation of Education Booklets}

\section{Evaluation Category}

1. How easy is it to read this booklet?

2. How much do the drawings help in understanding the information?

3. How easy is it to understand this booklet?

4. How well does the booklet meet your need for information on this topic?

5. How useful to you is the booklet for taking care of your diabetes?

6. How much will this information help you improve the way you care for your diabetes?

\begin{tabular}{ccccc} 
Extremely & A Lot & Moderately & A Little & Not at All \\
65 & 22 & 6 & 2 & 5 \\
26 & 46 & 22 & 5 & 1 \\
53 & 36 & 7 & 1 & 2 \\
37 & 49 & 10 & 3 & 0 \\
31 & 48 & 17 & 1 & 2 \\
29 & 41 & 19 & 8 & 3 \\
\hline
\end{tabular}


positive statements about the information given, format, and method of presentation.

\section{Discussion}

In general, the "Life with Diabetes" booklets received favorable evaluations from health professionals before being made available to patient evaluators. Comments in this formative or process evaluation were used to revise and improve the booklets before publication. Patients generally found that the booklets were helpful and easy to read and understand and met their information needs. Patients' comments also were used during revision of the booklets to improve them.

The self-administered questionnaire method is inexpensive; requires less time than interviewing individual health professionals or patients; maintains anonymity, thus enhancing openness of the responses; and is easy to administer. A disadvantage of this method is that the self-selection of respondents (participation was voluntary) could result in some bias.

An ideal summative evaluation also would include an assessment of the impact of the booklets on patients' knowledge and behavior. One way to accomplish this, for example, would be to randomly assign patients to one of two groups: (1) group receiving the regular program, whether through a small group class or one-to-one instruction, and (2) group receiving the booklets as their primary source of information. Evidence of the effectiveness of the booklets might be indicated if patients who received only the booklets attained knowledge and skill levels equal or superior to those of the regular instruction group. Although we have not been able to conduct as rigorous an outcome (summative) evaluation of the booklets as just outlined, a separate evaluation of the entire inpatient education program using patients as their own controls in a pretestposttest, pre-experimental design suggested that a teaching program that employed the booklets seemed to help patients to learn. ${ }^{9}$

Each patient was given a copy of the booklet "Diabetes Defined" on admission; other booklets in the series were given to them before discharge when the content was appropriate for them. Typically the booklets were distributed after the class that covered similar content. Results of a diabetes knowledge test indicated that patients' knowledge significantly improved from admission to discharge from the DCU. ${ }^{9}$ At admission, patients on the average answered $61 \%$ of the items correctly; at discharge, the average was $78 \%$. Patients improved 0.94 standard deviation (SD) units, or the average person at discharge obtained a score equivalent to the person who scored in the 83rd percentile of performance at admission to the DCU. Rossi and Wright ${ }^{5}$ observed that a $0.50 \mathrm{SD}$ improvement in achievement scores is considered a conventional measure of practical significance. Similarly, the National Institute of Education task force ${ }^{10}$ observed that usually one-third (0.33), but at times as little as one-fourth $(0.25)$, SD improvement is considered educationally significant.

Although this effect is a result of the total program and cannot be solely attributed to use of these booklets, the content of the booklets is included in both the formal patient education group classes and in the individualized learning that occurs through patient-provider interactions. The booklets also offer a thorough review and reference for patients while on the DCU and after discharge.
This evaluation has attempted to meet the four important standards of an evaluation (utility, feasibility, propriety, and accuracy) identified by the Joint Committee on Standards for Educational Evaluation ${ }^{11}$ : Utility-timeliness (evaluation both before and after final publication of the booklets) and success in meeting educators' and patients' needs; feasibility-efficient use of the evaluators' time and cost-effectiveness (indicated by decision to use self-reporting); propriety-ensuring anonymity of respondents; and accuracy-assessing the important, practical features of the booklets (from both educators' and patients' perspectives) and using a reliable and validated knowledge test.

Because new developments in diabetes care are periodically incorporated into existing or new titles, this evaluation process is being used on an on-going basis to improve these materials.

\section{References}

1. Reference Manual for Evaluation of Diabetes Education Program American Association of Diabetes Educators, Pitman, NJ, 1982.

2. Guidelines for Diabetes Care. American Diabetes Association/American Association of Diabetes Educators, New York/Pitman, NJ, 1981

3. Centers for Disease Control: An Evaluation Handbook for Health Education Programs in Diabetes. Center for Health Promotion and Education, Atlanta, 1983

4. Bloom BS, Hastings JT, Madaus, GF: Handbook on Formative and Summative Evaluation of Student Leaming. New York, McGraw-Hill Book Co, 1971.

5. Rossi P, Wright S: Evaluation research: An assessment of theory, practice, and politics. Eval $Q$ 1:5-52, 1977.

6. Scriven M: The methodology of evaluation, in Tyler RW, et al (eds) Perspectives on Curricular Evaluation. Chicago, Rand McNally, 1967.

7. Michigan Diabetes Research and Training Center: Life with Diabetes: A Series of Patient Education Booklets. Media Library, University of Michigan Medical Center, Ann Arbor, 1985.

8. Pretesting in Health Communications: Methods, Examples, and Resources for Improving Health Messages and Materials. National Cancer Institute, US Department of Health and Human Services, 1984.

9. Howard M, Bamett C, Chon M, et al: Retention of Knowledge and SelfCare Skills After an Intensive Inpatient Diabetes Education Program. University of Michigan Diabetes Research and Training Center, Ann Arbor, 1984.

10. Tallmadge GK: The Joint Dissemination Review Panel Ideabook. National Institute of Education and US Office of Education, Washington, DC, 1977.

11. Joint Committee on Standards for Educational Evaluation: Standards for Evaluations of Educational Programs, Projects, and Materials. New York, McGraw-Hill Book Co, 1981. 